\title{
PESSIMISMO E EUDEMONOLOGIA: SCHOPENHAUER ENTRE PESSIMISMO METAFÍSICO E PESSIMISMO PRAGMÁTICO
}

\author{
Vilmar Debona* \\ debonavilmar@gmail.com
}

RESUMO Como entender uma teoria da felicidade enquanto sabedoria de vida, elaborada a partir de noções como as de uso prático da razão e de caráter adquirido, no pensamento do grande metafísico pessimista que certamente foi Schopenhauer? O presente artigo sustenta a hipótese de que o pessimismo schopenhaueriano pode ser melhor compreendido se considerado, por um lado, como um pessimismo metafísico, e, por outro, como um pessimismo pragmático. Para tanto, procuro mostrar em que medida a consideração da peculiar eudemonologia do pensador é fundamental para uma compreensão mais abrangente de seu pessimismo.

Palavras-chave Schopenhauer, pessimismo metafísico, pessimismo pragmático, eudemonologia, metafísica da vontade, sabedoria de vida.

ABSTRACT How can a theory of happiness, based upon the practical use of reason and acquired character, be understood in the thought of Schopenhauer, the great pessimist metaphysic? This article aims to prove that Schopenhauer's pessimism can be better understood if considered, on the one hand, as metaphysical pessimism and, on the other, as pragmatical pessimism. Thus, I 
seek to show that the consideration of Schopenhauer's singular eudemonology is fundamental to fully understand his pessimism.

Keywords Schopenhauer, metaphysical pessimism, pragmatical pessimism, eudemonology, metaphysics of the will, life wisdom.

\section{Considerações preliminares}

Se Schopenhauer delimitou os parâmetros e critérios de sua fundamentação da moral e de sua teoria do conhecimento, ele não fez o mesmo em relação ao que se convencionou chamar de seu pessimismo, nem especificou em que medida esse pessimismo se relacionaria com noções da ética, da estética, do ascetismo e, menos ainda, da eudemonologia. Com efeito, o filósofo que geralmente é apresentado pela literatura e pela historiografia como o grande metafísico pessimista de todos os tempos, que considerou ser esse "o pior dos mundos possíveis", elaborou também uma eudemonologia a partir de sua noção de sabedoria de vida (Lebensweisheit), assim como esboçou um manual de regras para a "arte de ser feliz". Além do mais, sabe-se que, em todos os seus escritos, Schopenhauer empregou apenas três vezes o termo pessimismo (Pessimismus) para se remeter de forma direta à sua própria doutrina; nenhuma dessas ocasiões consta da obra publicada em vida. ${ }^{1}$

O termo pessimismo, do latim pessimum, o pior ${ }^{2}$ (tendo, por conseguinte, a noção de otimismo como seu oposto), é geralmente tomado em termos filosóficos no sentido ontológico, ou seja, é próprio de visões de mundo cujos princípios cardinais consideram o "não ser" como preferível ao "ser". Em termos especificamente schopenhauerianos, o pessimismo, visto a partir do conjunto das obras do pensador, pode ser lido como a concepção que considera esse como "o pior dos mundos possíveis", conforme destaca amplamente o próprio Schopenhauer, pela admissão de que tal mundo só poder ser definido a partir da dor e do sofrimento. ${ }^{3}$

1 Em 1828, no fragmento póstumo 66 dos "Adversaria" (cf. HN III, p. 464); em 1833, no fragmento póstumo 49 dos "Pandectae II" (cf. HN IV, p. 160); e, em 1855, na carta de 15 de julho a Julius Frauenstädt (cf. SW, "Briefwechsel", XV, p. 393).

2 Cf. GERHARDT, V. "Pessimismus". In: Historisches Wörterbuch der Philosophie. Hrsg. von J. Ritter; K. Gründer. Band 7. Basel: Schwabe \& Co. Verlag, 1989, pp. 386-395; cf. STÄGLICH, H. "Zur Geschichte des Begriffs Pessimismus". In: Schopenhauer-Jahrbuch. Bd. 34, 1951/1952, pp. 27-37.

3 Sobre a noção geral de pessimismo no pensamento de Schopenhauer, a bibliografia é extensa. Limito-me a mencionar: KÖHLER, F. "Schopenhauer und das Wesen des Pessimismus und Optimismus". Langensalza: H. Beyer, 1926; INVERNIZZI, G. "Il pessimismo tedesco dell'Ottocento: Schopenhauer, Hartmann, Bahnsen e Mainländer e i loro avversari”. Firenze: La Nuova Italia, 1994, pp. 19-43; e DÖRPINGHAUS, A. "Mundus 
Em grande medida, foram os membros da chamada Schopenhauer-Schule (Escola de Schopenhauer, formada por discípulos do filósofo stricto e lato sensu ${ }^{4}$ ) que se detiveram na natureza do pessimismo do mestre e se confrontaram com a questão em um amplo debate que perpassou a segunda metade do século XIX na Alemanha. Muito por influência desse debate, as caracterizações que tomam o pensamento schopenhaueriano como pessimista geralmente justificam tal adjetivação a partir de concepções e conceitos da metafísica da vontade. No entanto, se é assim, como um pessimismo unicamente metafísico poderia abarcar as contribuições de Schopenhauer sobre a felicidade em termos de sabedoria de vida, elaboradas a partir do que o próprio filósofo chamou de um "desvio da metafísica"? Isto é, se quisermos alcançar uma visão pormenorizada e criteriosa da natureza do pessimismo schopenhaueriano teríamos que, naturalmente, indagar se a passagem da esfera metafísica para a empírico-eudemonológica significaria uma passagem para alguma espécie de "otimismo" e, por conseguinte, se isso contradiria ou não o âmago de uma filosofia que postula um mundus pessimus. O referido "desvio da metafísica" representaria também um "desvio do pessimismo"? Ou, se não é assim, qual seria a natureza do pessimismo schopenhaueriano do âmbito da sabedoria de vida, dado que por certo já não poderia se tratar mais de um pessimismo exclusivamente metafísico?

Para investigar a questão, parto da ideia de que se o chamado pessimismo schopenhaueriano é ineludível, ele possui variantes importantes. Afinal, como sustentar alguma afinidade significativa entre um pensamento que considera a ação humana a partir de uma ontologia pessimista - segundo a qual este é "o pior dos mundos possíveis" (Schopenhauer, WWV II, Kap. 46, p. 667), 5 "o maior erro do homem foi ter nascido" e a busca pela felicidade é um "erro inato" - e uma filosofia dedicada à elaboração sistemática de uma eudemonologia para o homem alcançar a maior parcela possível de felicidade?

Frente a esta questão, o objetivo central do presente artigo é mostrar em que medida estas duas esferas da filosofia schopenhaueriana não são discrepantes, a

pessimus: Untersuchungen zum philosophischen Pessimismus Arthur Schopenhauers". Würzburg: Königshausen \& Neumann, 1997.

4 Cf. FAZIO, D. "La scuola di Schopenhauer: i contesti". In: La scuola di Schopenhauer: testi e contesti. A cura del Centro interdipartimentale di ricerca su Arthur Schopenhauer e la sua scuola dell'Università del Salento. Lecce: Pensa Multimedia, 2009, pp. 13-212; Ver também FAZIO, D. "La 'scuola' di Schopenhauer. Per la storia di un concetto". In: Arthur Schopenhauer e la sua scuola. A cura di F. Ciraci, D. Fazio e F. Pedrocchi. Lecce: Pensa Multimedia, 2007, pp. 35-76.

5 A passagem completa é a seguinte: "Às demonstrações claramente sofísticas de Leibniz de que este mundo seja o melhor dos mundos possíveis, pode-se até mesmo contrapor séria e honestamente a demonstração de que se trata do pior dos mundos possíveis" (Schopenhauer, WWV II, Kap. 46, p. 667, grifo do autor).

6 El delito mayor del hombre es haber nacido, formulação de Calderón de la Barca (de "La vida es sueño") que Schopenhauer cita variadas vezes em toda a sua obra (Cf., por exemplo, MVR I, § 51, p. 344; Idem, § 63 , p. 453; WWV II, Kap. 48, p. 690). 
ponto de podermos considerar que a eudemonologia é suplementar em relação ao pessimismo metafísico. A questão basilar a que pretendo responder repousa justamente sobre a ideia de como seria possível conciliar as duas diferentes instâncias filosóficas acima referidas - que podem ser chamadas, respectivamente, de esfera teórico-metafísica e de esfera pragmático-eudemonológica -, cujos papéis são tão diversos quando tomados em vista do chamado pessimismo schopenhaueriano.

\section{Alguns posicionamentos sobre a questão}

A problemática aqui apresentada sobre o lugar da eudemonologia ante o pessimismo em Schopenhauer já recebeu importantes posicionamentos ou comentários de célebres nomes da Filosofia. Em geral, tais posicionamentos detêm-se, por um lado, em contestar a possível complementariedade que noções da eudemonologia representariam perante a metafísica, ou, por outro, em legitimar a primeira em face da última. Mas, para tanto, grande parte das reflexões restringe-se em tomar como ponto de partida as declarações de Schopenhauer (cf. 1851 b, p. 1) sobre a superioridade de sua metafísica (sua "filosofia propriamente dita") diante do caráter secundário atribuído por ele aos escritos sobre a felicidade. Limita-se a considerar a questão a partir dos "Aforismos para a sabedoria de vida" (doravante, "Aforismos") em confronto quase exclusivo com teses de "O mundo como vontade e como representação" (doravante, "O mundo"), tomando o fato de o primeiro texto pertencer aos "Parerga e paralipomena", "escritos filosóficos menores" (conforme reza o subtítulo da obra), como único critério para validar a atribuição de uma importância menor à filosofia práticopragmática ali desenvolvida. Esta é também a tendência de comentadores que simplesmente não reconhecem a Eudemônica schopenhaueriana como campo relevante para o debate do pessimismo e da ação humana. Como exemplo deste último caso, podemos citar a leitura de Deussen que, detendo-se no âmbito teórico-metafísico, chega até mesmo a lamentar o fato de os "Parerga e paralipomena", por desenvolverem (na maioria de seus textos) o ponto de vista "comum" e empírico da filosofia, terem sido a obra mais lida de Schopenhauer (cf. Deussen, 1980, p. 159). No horizonte doxográfico da literatura ocidental, Nietzsche pode ser considerado o grande influenciador da interpretação que toma o filósofo como um pensador que teria espalhado pela humanidade o seu "pessimismo encharcado de perfume fúnebre" (Nietzsche, 2008, p. 59), o que

7 No entanto, vale ter presente a ironia nietzscheana sobre a autenticidade do "verdadeiro pessimista" que tocava flauta após as refeições: “Um pessimista, um negador de Deus e do mundo [...], que diz 'sim' à moral 
teria ocorrido não apenas devido à definição schopenhaueriana de existência como dor e sofrimento, mas também devido à concepção de negação da vontade pela contemplação estética, no sentido identificado pelo autor de "Para a genealogia da moral” como um "ideal ascético" (cf. Nietzsche, 1998, § 6 e 7, pp. 93-97). ${ }^{8}$ Desde estas perspectivas, tudo se passa como se para além do horizonte da negação da vontade, da desaprovação da vida, da ascese mística, do quietismo, Schopenhauer não tivesse oferecido nada de relevante para a consideração da vida e da ação humanas. Trata-se, em suma, de leituras - definidoras de uma imagem tradicional de Schopenhauer - que nada ou pouco reconhecem do aparato empírico-pragmático-eudemonológico desta filosofia, encerram-se nas cercanias do pessimismo metafísico de "O mundo", e só conseguem tomar as considerações do filósofo sobre a felicidade, sobre o uso prático da razão e sobre a vida em sociedade como riscos de otimismo e, por conseguinte, de contradição interna.

Na contramão dessas análises, Volpi, sobretudo nas variadas apresentações de suas edições dos póstumos de Schopenhauer, vê as teses sobre o conhecimento de si e a sabedoria de vida como noções "compactas e unitárias" em relação àquelas da metafísica. Mesmo que não tenha se detido em questões e conceitos específicos, Volpi não trata os textos de eudemonologia - tanto os esboços de Eudemonologia dos "Manuscritos berlinenses" (1826-1829) quanto os "Aforismos" (1851) - como escritos menos dignos de atenção que os textos de metafísica. Considera-os, isso sim, como

pontos de sutura por meio dos quais Schopenhauer recompõe a metafisica do pessimismo de $O$ mundo com a sabedoria de vida dos Parerga e paralipomena, a filosofia teorética com a filosofia prática, a dimensão especulativa com a dimensão popular de seu sistema. Consolida-se, assim, a ideia de que a filosofia tem de ser entendida também - muito além da construção do edifício teórico da metafísica do pessimismo, que ensina que a vida não é bela - como sabedoria e arte de viver (Volpi, 2004, p. XI, grifos meus). ${ }^{9}$

Nesta mesma linha interpretativa e inspirado na leitura de Horkheimer sobre a compaixão schopenhaueriana, ${ }^{10}$ Lütkehaus (1980, pp. 50-60) sustenta que o pessimismo schopenhaueriano não é um quietismo, mas pode ser visto

e toca flauta, à moral do laede neminem: como? Este é verdadeiramente - um pessimista?" (Nietzsche, 2005 , § 186, p. 75).

8 No "Crepúsculo dos ídolos", Nietzsche afirma: "Schopenhauer ensinou o 'desvencilhar-se da vontade' como o propósito geral da arte, e venerou o 'inclinar à resignação' como a grande utilidade da tragédia. - Mas isso - já o dei a entender - é ótica de pessimista e 'mau olhado' [...]" (Nietzsche, 2006, § 24, p. 78; ver também: ibidem, X, § 5, p. 106).

9 Ver também VOLPI, F. "Apresentação". In: SCHOPENHAUER, A. A arte de ser feliz. São Paulo: Martins Fontes, 2008, p. X.

10 Cf. HORKHEIMER, M. “Die Aktualität Schopenhauers”. In: Schopenhauer-Jahrbuch. Bd. 42, 1961, pp. 12-25. 
como uma filosofia da "práxis do "como se"”, assim como a compaixão pode ser entendida em termos de "identificação ativa". Dessa forma, a eudemonologia negativa, que ensina a viver ponderada e racionalmente, e a compaixão como "mística prática" formariam uma mesma base argumentativa que aponta como Schopenhauer não se limitou à metafísica de uma "patodiceia ontológica", mas erigiu amplas reflexões e formulações no sentido de uma filosofia prática.

Minha interpretação procura sustentar a hipótese de que a questão referida acima pode ser analisada pela diferenciação entre o que chamo de pessimismo metafísico e de pessimismo pragmático. Principalmente devido à especificidade de noções próprias da sabedoria de vida (tais como as de caráter adquirido, razão prática e prudência) diante de noções metafísicas (como a de predomínio do egoísmo no âmbito das motivações da ação, imutabilidade do caráter etc.), esta diferenciação auxiliaria em uma possível definição da genérica noção de pessimismo schopenhaueriano, mas também na análise sobre se ela permanece a mesma, é modificada ou adquire outras semânticas quando considerada no patamar empírico-pragmático-eudemonológico. Em termos gerais, o pessimismo metafísico responderia à ideia da impossibilidade de uma felicidade duradoura. Já o pessimismo pragmático corresponderia à ideia de que a aposta na sabedoria de vida, mesmo que delimite os horizontes de uma felicidade relativa, não equivale a promessas de grandes êxitos no plano prático ou a um otimismo em sentido estrito, mas ao pessimismo de uma eudemonologia eufemística, de uma vida "menos infeliz" pelo uso prudente da razão.

\section{O pessimismo metafísico e alguns de seus pressupostos}

Os procedimentos adotados por Schopenhauer para fundamentar a moralidade podem servir, em grande medida, como parâmetro para um delineamento de seu pessimismo. Isto pode ser afirmado nos seguintes termos: a identificação da autêntica ação moral (ou de seu fundamento metafísico) com o rompimento do princípio de individuação enquanto princípio que é sinônimo de ilusória multiplicidade e de pecaminosidade já pressupõe um pessimismo metafísico referente aos ditames da individuação, esta que, no entanto, é condição de todos os seres como afirmadores da vontade e, ao menos enquanto estes estiverem submetidos a ela, determinará inevitavelmente as suas ações. A finitude de todos os fenômenos encerra a própria condição do indivíduo como prisioneiro de si mesmo e refém do egoísmo natural alheio, domínio no qual Alles Leben ist Leiden (toda vida é sofrimento) (cf. Schopenhauer, MVR I, § 56, p. 400) e do qual só se pode libertar pela renúncia da vontade de vida mediante uma renúncia de si mesmo. Nesse sentido, a princípio, o pessimismo se referiria 
apenas ao lado da afirmação de cada individualidade no tempo e no espaço, em cuja esfera tudo o que se faz remete-se, direta ou indiretamente, ao egoísmo e ao interesse próprios. A ultrapassagem desse domínio já representaria uma superação do pessimismo.

Por ora, se levamos em conta que a premissa segundo a qual o viés traçado em vista da fundamentação da moral não se separa de uma "fundamentação" do pessimismo schopenhaueriano, e vice-versa, ${ }^{11}$ então esse pessimismo também pode ser denominado, com razão, de pessimismo metafísico. Para a justificação desse pressuposto, bastaria, a princípio, a consideração de uma das teses centrais dessa filosofia, a saber, a reprovação do próprio mundo devido à constatação de sua dinâmica volitiva e do predomínio da dor nele implícito, o que significa o mesmo que a constatação de uma cosmologia como um complexo de desejos eternamente insaciáveis, motivadores de disputas, de dores, de sofrimentos e signos de corrupção e morte. Do ponto de vista objetivo, e na medida em que a vontade é tida como vontade de vida, a natureza não passa de um contínuo tender (Streben) à manutenção dessa vida, o que se dá por uma incessante satisfação de desejos. Do ponto de vista subjetivo, uma eventual satisfação de desejos traduz-se em sentimentos de prazer. Cada desejo ou falta é identificado como dor e sofrimento, "a base de todo querer é desejo, ou seja, dor, à qual o homem é vinculado desde sua origem e por natureza" (Schopenhauer, MVR I, § 57, p. 401). O prazer é, então, sempre negativo; ele só pode se dar após a admissão da realidade de um desejo ou de um sofrimento: "Toda satisfação, ou aquilo que comumente se chama felicidade, é própria e essencialmente falando apenas negativa, jamais positiva" (ibidem, p. 411, grifo do autor). De acordo com isso, o mundo, tal como é, não deveria existir; ele seria, antes, um erro ou um equívoco, já que seu caráter geral não consente à vontade satisfações duradouras; isto é, o seu "não ser" seria mais positivo do que o seu existir (cf. Schopenhauer, WWV II, Kap. 41, p. 531). Por isso o apreço de Schopenhauer pela formulação de Calderón de la Barca, segundo a qual el mayor delito del hombre es haber nacido. Que cada existência seja um erro que deveria ser evitado é algo atestado, do ponto de vista formal, por ela mesma: "[A existência] é uma queda contínua do presente no passado morto, um morrer constante" (Schopenhauer, MVR I, § 57, p. 401). Do ponto de vista físico, da mesma forma que o andar é uma queda continuamente evitada, e o respirar, o alimentar-se, o aquecer-se, o dormir etc. é um sucumbir continuamente adiado,

11 Nesse sentido, Invernizzi (1994, pp. 32-33) afirma que “[...] o pessimismo schopenhaueriano tem, no mínimo, uma estreita ligação com a moral dessa filosofia e, com efeito, Schopenhauer insiste, em muitas ocasiões, na necessidade de se considerar a realidade em seu complexo do ponto de vista do seu significado moral". 
assim também a vida corpórea é um morrer continuamente evitado (cf. idem). Eis uma concepção ineludível enquanto ponto de partida para a consideração do problema da fundação desse pessimismo, ou para o reconhecimento de um mundus pessimus em sua oposição frontal, constatada empiricamente, em relação às doutrinas defensoras do "melhor dos mundos possíveis".

Contudo, este pessimismo metafísico pode ser delimitado a partir de um critério conceitual mais específico na medida em que se reconhecem como seu pano de fundo elementos da fundamentação schopenhaueriana da moral. A partir deste parâmetro, tal pessimismo metafísico poderia ser identificado sob três principais pressupostos metafísico-morais explicitados pelo próprio filósofo. Os três referidos pressupostos seriam:

1. O reconhecimento do egoísmo e da maldade como tendências intrínsecas ou como instintos e impulsos fundamentais (Grundtriebfedern) ao caráter do homem: "A motivação principal e fundamental, tanto no homem quanto no animal, é o egoísmo, ou seja, o ímpeto para a existência e o bem-estar" (Schopenhauer, 1840 , p. 120). Não se trata, então, de um "pessimismo antropológico", pois apesar de o egoísmo animal não consistir em um "interesse próprio" (Eigennutz) e planejado, ele ainda seria um "amor-próprio" (Selbstsucht). Na natureza humana, porém, o egoísmo interesseiro não conhece limites: "Cada um traz em si o único mundo que conhece e de que sabe como sua representação, e por isso esse mundo é o seu centro [...]. É assim que este egoísmo, que está entre um homem e outro como uma larga cova, cresce sempre mais" (ibidem, p. 122). Ao sublinhar essa "grandeza do egoísmo" (die Größe des Egoismus), Schopenhauer chega à nefasta consideração de que "alguns homens seriam capazes de assassinar um outro só para engraxar suas botas com a gordura dele" (ibidem, p. 124). E, por mais que os elementos céticos em relação à existência de um fundamento natural para a ética e a constatação da corrupção moral do mundo não sejam suficientes para se negar qualquer possibilidade de algum recanto para a moralidade genuína, o são "para moderar nossa expectativa sobre a disposição moral do ser humano [...] e considerar que a motivação para o bem não pode ser tão poderosa" (ibidem, p. 117). Esta desconfiança pessimística é ainda maior quando se considera que a manifestação da tendência de antimoralidade intrínseca em cada caráter é sempre ocultada pela ordem legal, pela necessidade da honra, pela cordialidade, ou mesmo pela educação, esta que é preponderantemente díspar em relação à realidade e que as crianças recebem logo cedo. Não fossem estes "disfarces" legais e civis, a maldade e a crueldade estariam na ordem do dia. Daí ser preciso "ler histórias criminais e descrições de situações anárquicas [...], e ver os milhares que se acotovelam uns aos outros num transitar pacífico [...], como se fossem tigres e lobos cujas 
mandíbulas estivessem seguras por forte focinheira" (ibidem, p. 118), para se saber o que é propriamente o ser humano no aspecto moral.

2. A impossibilidade de melhoria do caráter, somada à necessidade como regente das motivações e das ações, o que faz com que a compaixão, enquanto motivação casual e sem poder ser promovida, fique à mercê de seu encontro com um caráter - o caráter inteligível, inato e imutável - que seja receptivo a esta classe de motivos. O pessimismo delineado nesses termos se deixaria identificar, então, pelo não reconhecimento de êxito por parte de experiências, cultura, religião ou qualquer doutrinamento, caso estes visem a imutável e constante individualidade. Aqui é necessário pressupor os aspectos elementares da doutrina schopenhaueriana do caráter tomada enquanto caráter inteligível, caráter empírico ${ }^{12} \mathrm{e}$, ainda, como caráter adquirido (este que será abordado no âmbito do pessimismo pragmático). A tese da fixidez e da constância do caráter se faz presente em todas as fases da produção filosófica do pensador: ela é formulada ainda no fragmento póstumo 159 , de $1814 ;{ }^{13}$ é pressuposta durante a formulação da metafísica da vontade e a fundação da ética; e é novamente repetida no Vol. II dos "Parerga e paralipomena": "a característica [da vontade individual] é inata e incapaz de qualquer melhoramento (Verbesserung) mediante a formação" (Schopenhauer, 1851a, § 117, p. 73). A insistência nesta perspectiva não deixa de se reportar diretamente à noção metafísica de caráter e pode ser notada também quando se considera a defesa de que o autêntico critério de distinção fundamental entre uma religião e outra, enaltecido pelo pensador em diversos momentos, não consiste

no fato de serem elas [as religiões] monoteístas, politeístas, panteístas ou ateias, mas somente no fato de serem otimistas ou pessimistas, ou seja, de conceberem a existência deste mundo como justificada em si mesma, e por isso a louvarem e a exaltarem, ou ao contrário, de considerarem tal existência como algo que só pode ser compreendido como fruto de nossa culpa e que, então, não deveria existir na medida em que se reconhece que dor e morte não podem residir na eterna, original e imutável ordem das coisas [...] (Schopenhauer, WWV II, Kap. 17, p. 188, grifos meus).

12 De forma sumária, o caráter inteligível diz respeito a um ato de objetivação da vontade como coisa em si, uma individualização da vontade genérica em seus mais variados fenômenos; um caráter inato, imutável e individual. Já o caráter empírico apenas manifesta o caráter inteligível no tempo e no espaço e consiste num impulso natural e inconsciente da vontade individual. $\mathrm{O}$ caráter adquirido corresponde à ideia do processo de autoconhecimento e das experiências adquiridas do caráter individual e inalterável.

13 A formulação é a seguinte: "O caráter moral [do homem] permanece sempre o mesmo durante toda a vida [...]. Portanto, nem experiência, nem filosofia e nem religião podem melhorá-lo" (Schopenhauer, HN I, "Die Genesis des Systems", § 159, p. 91). 
O cristianismo, com sua doutrina da "queda do homem", do pecado original, da perversidade e da perdição natural humanas, juntamente com a doutrina da expiação dessa condição por obra do Redentor, apresenta-se como autêntico pessimismo (cf. Schopenhauer, 1851a, § 181, p. 269). Justamente por isso a visão pessimista schopenhaueriana se oporia ao otimismo notado no hebraísmo e no islamismo, mas coincidiria com o brahmanismo e com o budismo, conforme sustentado pelo próprio filósofo.

3. A indicação da autêntica ação moral como ação misteriosa: "Este processo é, eu repito, misterioso, pois é algo de que a razão não pode dar conta diretamente e cujos fundamentos não podem ser descobertos pelo caminho da experiência" (Schopenhauer, 1840, p. 163, grifos do autor). Também neste sentido, muito embora a superação do "Véu de Maja" possa representar a superação do próprio pessimismo empiricamente constatado, tratar-se-ia de um pessimismo que se justificaria pela oposição schopenhaueriana ao otimismo em relação à produção da ação moral: a imediatez das ações altruístas não pode ser ensinada e disseminada com uma quantidade e intensidade cada vez maiores. $\mathrm{O}$ argumento de Schopenhauer, quanto a este ponto, é preciso:

Se as muitas instituições religiosas e os esforços moralizantes não tivessem errado o alvo, a metade mais velha da humanidade teria de ser significativamente melhor do que a mais jovem, pelo menos na média. Há, porém, tão poucos traços disto que, inversamente, esperamos antes algo bom dos jovens do que dos velhos, que ficaram piores com a experiência (ibidem, p. 194).

É diante dessas teses, entre outras, que se pode captar o diferencial que Schopenhauer atribui à sua fundamentação da ação e da existência humanas em relação ao "otimismo de todos os sistemas filosóficos", expressão empregada pelo próprio filósofo em "Sobre a vontade na natureza" (1911-1941d, p. 423). Desse modo, embora o pensador não tenha usado o termo Pessimismus de forma direta para com ele englobar os assuntos dos três tópicos acima elencados, a textual oposição ao otimismo dos "outros sistemas" permite que consideremos tais tópicos como legítimos pressupostos e conteúdos do chamado pessimismo metafisico schopenhaueriano.

\section{A hipótese do pessimismo pragmático no âmbito da eudemonologia e algumas de suas expressões}

Para além do aparato metafísico que fundamenta o chamado pessimismo schopenhaueriano, há nessa filosofia considerações feitas sob uma perspectiva empírico-eudemonológica tanto da ação humana quanto da existência em geral. 
Para assumir esse outro horizonte filosófico, o pensador assevera, nos “Aforismos para a sabedoria de vida" (cf. 1851b, pp. 1-2), um "desvio total" "do ponto de vista superior, ético-metafísico", o que nos permite afirmar que a questão da articulação de uma sabedoria de vida com o seu pensamento metafísico não foi ignorada pelo próprio Schopenhauer. Com efeito, a incoerência que porventura saltasse aos olhos do leitor que passasse do final do Tomo II de "O mundo" (principalmente do capítulo 49), onde lemos a defesa de que nosso "único erro inato" (cf. WWV II, Kap. 49, p. 729) consiste em acreditarmos que existimos a fim de sermos felizes, para o capítulo V dos "Aforismos", no qual encontramos 53 máximas de sabedoria de vida, decerto seria pelo fato de este mesmo leitor ter desconsiderado as determinantes observações da Introdução dos mesmos "Aforismos", esclarecimentos metodológicos que permitem notarmos a coerência entre a abordagem metafísica e a abordagem propriamente eudemonológica da existência humana. Nesta Apresentação (1851b, pp. 1-2), o pensador afirma:

Se a vida humana corresponde, ou simplesmente pode corresponder ao conceito de tal existência [feliz], é uma questão que minha filosofia nega; ao contrário, a eudemonologia pressupõe a sua afirmação. Esta, na verdade, baseia-se no erro inato, cuja repreensão abre o capítulo 49 do Vol. II de minha obra principal. ${ }^{14}$ Não obstante, para poder abordar o tema [da eudemonologia], tive de desviar-me totalmente do ponto de vista superior, ético-metafísico (habe ich daher gänzlich abgehen müssen von dem höheren, metaphysisch-ethischen Standpunkte), ao qual conduz a minha filosofia propriamente dita (meine eigentliche Philosophie). Por conseguinte, toda a discussão aqui conduzida baseia-se, de certo modo, numa acomodação (auf einer Ackommodation), já que permanece presa ao ponto de vista comum, empírico, cujo erro conserva. Logo, também o seu valor só pode ser condicional, pois até mesmo a palavra eudemonologia não passa de um eufemismo (grifos meus).

Esse "desvio total" já havia sido anunciado anteriormente, num fragmento póstumo dos Foliant $I I,{ }^{15}$ e, se o reconhecermos em termos de um cuidado metodológico de Schopenhauer, tratar-se-ia de um "desvio" que garantiria as duas perspectivas desenvolvidas por sua filosofia, a metafísica e a eudemonológica, estas que, segundo Malter $(1991, \S 4)$, consistiriam no próprio motor desse pensamento. Para tanto, o referido "desvio" se apresentaria como estratégico: a admissão de que, por um lado, tem-se a "verdadeira filosofia" (ou uma filosofia

14 Trata-se da seguinte passagem: "Há somente um erro inato: pensar que existimos para sermos felizes. É inato porque coincide com nossa própria existência. Todo o nosso ser é apenas a sua paráfrase; e nosso corpo, o seu monograma. Não somos mais que vontade de viver; a sucessiva satisfação de todo o nosso querer é o que entendemos pelo conceito de felicidade" (WWV II, Kap. 49, p. 729).

15 A formulação encontra-se numa nota e diz o seguinte: "Desvio-me, aqui, completamente do ponto de vista ético-metafísico, superior e mais verdadeiro [...]" (HN III, "Foliant II", § 124, p. 268). No original, "Ich sehe nämlich hier ganz ab von dem höheren und wahreren metaphysisch ethischen Standpunkt" (ibidem). 
"propriamente dita", eingentliche Philosophie), pautada sob o ponto de vista "superior", e, por outro, a eudemonologia, cujo valor seria condicional e "inferior" (em relação à "superioridade" metafísica), não implicaria contradições ou conflitos de princípios filosóficos, mas asseguraria a suplementaridade de dois pontos de vistas. E, desse modo, mesmo que o subtítulo dos extensos "Parerga e paralipomena" os classifique como "Escritos filosóficos menores" (kleine philosophische Schriften), não se trataria de escritos "secundários", mas de aperfeiçoamentos do sistema de "O mundo", conforme veremos.

A teoria da felicidade esboçada por Schopenhauer está longe de defender um simples hedonismo ou uma busca pela felicidade (Glück) em sentido positivo, mas, como o próprio pensador sublinha, define-se enquanto uma eudemonologia negativa e eufemística. Isto é, esforça-se por apresentar noções que delimitariam um patamar "menos infeliz" da existência humana: "[...] quem quiser obter o balanço da própria vida em termos eudemonológicos, deve fazer a conta não segundo os prazeres que fruiu, mas segundo os males de que fugiu" (Schopenhauer, 1851b, p. 141). Trata-se de "evitar as penúrias e os golpes do destino, com a esperança de que, apesar de a felicidade perfeita ser inalcançável, podemos chegar àquela felicidade relativa que consiste na ausência de dor" (HN III, "Foliant I", § 124, p. 139, grifos meus). A possibilidade de uma felicidade em sentido positivo é descartada pela própria ontologia que concebe cada indivíduo em uma condição de eterna insatisfação, razão pela qual suas errâncias pelo mundo espelham inevitavelmente uma oscilação entre dor e tédio. Se a eudemonologia pressupõe a afirmação de uma "existência feliz", é só na medida em que esta última "deixa-se definir - considerada de modo puramente objetivo ou, antes, pela ponderação fria e madura - como algo preferível à não-existência" (Schopenhauer, 1851b, p. 1).

Do ponto de vista eudemonológico, o mundo e os homens continuam sendo tomados de forma imanente pela constante efetividade da autodiscórdia da vontade em seus fenômenos, geradores de dor e tédio. No entanto, ao invés de enaltecer os fenômenos do egoísmo natural, da impossibilidade de melhoria moral dos caracteres individuais, ou da ação moral imediata e desinteressada, $o$ filósofo parte da ideia de uma "acomodação" (Ackommodation) (cf. ibidem) por parte do indivíduo em relação ao destino e ao curso do mundo. A "acomodação" na perspectiva do "erro" da felicidade como concessão a um ponto de vista comum e cotidiano da filosofia indica, então, uma continuidade de pressupostos filosóficos - e não uma substituição -, constatação que motiva sobremaneira a indagação sobre a natureza dessa continuidade do pessimismo em termos eudemonológicos. 
Para uma resposta à questão, destaco, em primeira instância, a própria peculiaridade da questão da felicidade em termos schopenhauerianos: ela se põe como noção que não pode ser reduzida à ideia expressa pele mote "é impossível ser feliz", mas diz respeito, também, à impossibilidade de a limitarmos a um conjunto de máximas que possa ser adotado como uma receita asseguradora da felicidade humana, contrariamente ao que podem sugerir, num primeiro momento, as numerosas regras para a sabedoria de vida elaboradas pelo pensador, principalmente quando consideradas sob títulos como "a arte de ser feliz".

Ora, a admissão da impossibilidade referida acima já indica em que medida a hipótese de um pessimismo pragmático pode ser justificada. O aqui denominado pessimismo pragmático, ${ }^{16}$ ao se referir ao patamar da filosofia schopenhaueriana que não desconsidera - mas pressupõe - a ética e o pessimismo metafísicos, seria um "pessimismo para a vida no mundo", "aplicado" aos desdobramentos cotidianos e práticos da natureza imutável do caráter. No entanto, tratar-seia de uma espécie de pessimismo porque, ao reconhecer a necessidade das instrumentalizações fornecidas pelo intelecto para enfrentarmos o "mal de viver", Schopenhauer jamais toma tais instrumentalizações como definitivas.

Se os motivos que levam o pensador a elaborar uma eudemonologia eufemística são, no geral, pessimistas, os resultados dessa eudemonologia não podem ser assegurados e, por isso, também estes não podem denotar algum otimismo. É nesse sentido que Volpi (2008, p. X) afirma:

É justamente da convicção pessimista de que a vida, isto é, a finitude humana, oscila entre o tédio e a dor e de que este mundo não passa de um vale de lágrimas que Schopenhauer tira a exortação para enfrentar tal situação com a ajuda do precioso instrumento de que a mãe natureza nos dotou: o intelecto (grifos meus).

É impossível não ter presente, entretanto, a natureza secundária e limitada que Schopenhauer atribui a esse "instrumento" ante a natureza primária e sempre predominante da vontade irracional.

16 Barboza e Viesenteiner interpretam esta outra forma do pessimismo schopenhaueriano, respectivamente, como "otimismo prático" e como "grande pessimismo". Barboza (2006, p. XIII) considera que "podemos definir o pensamento de Schopenhauer como pendular, vale dizer, ele oscila continuamente entre pessimismo metafísico e otimismo prático". Por sua vez, Viesenteiner (2012, p. 9) afirma: "[...] no texto dos Aforismos, Schopenhauer também executa a trajetória que vai de um "ponto de vista superior, ético-metafísico", típico do pessimismo de $O$ mundo, para aquilo que denominamos de 'grande pessimismo', i.é., uma "acomodação" na vida que faz o autor se distanciar de um pessimismo absoluto, para vislumbrar as possibilidades de 'viver menos infeliz'. O 'grande pessimismo' é a prerrogativa daquele que agora pode executar em si as possibilidades de uma vida 'menos infeliz', somente porque vivenciou até a medula o próprio pessimismo, um 'otimismo prático' que é o privilégio daquele que foi suficientemente pessimista, experimentando cada um dos seus padecimentos na própria carne". 
O emprego aqui feito do termo "pragmático" refere-se ao próprio objetivo delineado por Schopenhauer de elaborar uma eudemonologia que tome as ações humanas como objeto de utilização e aplicação de máximas. A possibilidade de cada indivíduo dispor de "armas" ou "ferramentas" que o auxiliem em seu trâmite com o mundo é a base dos objetivos dos Aforismos e de toda a Eudemônica schopenhaueriana. Estes objetivos são cumpridos pela oferta de máximas que o próprio filósofo seleciona ou elabora: além das cinquenta e três máximas do capítulo V dos "Aforismos", Schopenhauer deixou mais cinquenta espalhadas em vários manuscritos póstumos, estas que foram reunidas posteriormente e publicadas sob o título de "A arte de ser feliz". O que convém notar aqui é que, se se trata de aplicações ou utilizações de regras de vida, então estas não podem ser destacadas apenas por serem realizadas do ponto de vista empíricoeudemonológico, mas também pelo fato de assumirem um viés "pragmático". Safranski (2010, pp. 494-495) faz uso de uma expressão semelhante ao aqui denominado pessimismo pragmático quando afirma: "Aqui [nos Aforismos] $o$ pessimismo de base é ‘amortecido' e a sabedoria para a sobrevivência e a autoafirmação, censuradas em outras ocasiões, recebem agora nova valoração pragmática" (grifos meus). Frisemos, contudo, que um pessimismo "amortecido" não significa um pessimismo superado. A indicação de ideais de sabedoria de vida representa uma alternativa pragmática para o indivíduo não ter que relegar tudo ao destino e à necessidade das ações, mas não é garantia de êxito diante das penúrias da existência, pois tem em vista uma certa "economia da dor" e não a eliminação das possibilidades da dor.

Mas vejamos, em termos mais específicos e a partir da letra de Schopenhauer, algumas das noções que justificariam a hipótese de um tal pessimismo pragmático. Afinal, quais seriam as expressões e a natureza do pessimismo do âmbito da teoria schopenhaueriana da felicidade?

1. Uma dessas expressões pode ser identificada nas observações do pensador sobre o alcance limitado do uso prático da razão, conceito este concebido em sintonia com a concepção estoica do mesmo, conforme lemos no $\S 16$ do Tomo I e no Cap. 16 do Tomo II de "O mundo". Há um intento em comum do Estoicismo e de Schopenhauer que consiste em indicar conselhos ao indivíduo diante do pressuposto das penúrias e percalços da existência. O cura sui dos estoicos romanos, especialmente de Sêneca, revela grande sintonia com o pensamento do autor dos Aforismos devido à pressuposição de ambas as filosofias sobre a inconstância e o sofrimento do indivíduo. Com efeito, Schopenhauer (MVR I, $\S 16$, p. 146) reconhece que "a ética estoica, tomada em seu conjunto, é de fato uma tentativa bastante apreciável e digna de atenção para usar a grande prerrogativa do homem, a razão, em favor de um fim importante e salutar, 
a saber, elevá-lo por sobre os sofrimentos e dores aos quais cada vida está exposta [...]" (grifos meus). Porém, o pensador não demora em indicar que, justamente por mirar a "bem-aventurança" a todo custo e exclusivamente às custas da razão, essa filosofia acaba se reduzindo a um "boneco de madeira", desprovida que é de representação intuitiva e de verdade poética interior. Em meio a tantos elogios à filosofia da Stoa, a referida crítica baseia-se na tese de que, se a sabedoria de vida e a prudência podem nos poupar de certas penúrias, isso não garante que elas poderiam nos legar a perfeição ou a beatitude eterna, conforme pretenderam os estoicos. É nesse sentido que o filósofo considera que "o sábio estoico não sabe aonde ir com sua sabedoria, e sua tranquilidade perfeita, contentamento, beatitude [...]" (ibidem, p. 148). Toda a capacidade que o uso prático da razão tem de dispor de conselhos e máximas não possui força suficiente para subtrair a condição volitiva humana. $\mathrm{O}$ fato de podermos colher e usar pragmaticamente "regras" de tranquilidade ou de sabedoria não faz com que tais possibilidades sejam supremas ou perfeitas, dado que é impossível prescindirmos do pressuposto da vontade incessante. Nesse sentido, se Schopenhauer indica limites na concepção estoica, é porque ele pressupõe a impossibilidade de um uso prático da razão redimir o homem dos sofrimentos intrínsecos à vida, uma vez que sempre haveria "uma contradição absoluta entre querer viver sem sofrer" (ibidem, p. 146).

2. Outra noção que denota a ideia de um pessimismo pragmático schopenhaueriano é a de que a felicidade depende muito mais do que se é e nem tanto do que se tem ou representa, sendo que o que se é, porém, não depende do indivíduo. Em 1828, na continuação do seu esboço de "Eudemonologia" (§ 270 dos "Foliant II"), Schopenhauer evoca diretamente a questão ontológica do caráter inato e imutável no rol do tratamento da felicidade, tratando-a no sentido de personalidade (Persönlichkeit), do que "alguém é". Trata-se da divisão de inspiração aristotélica (que também seria usada com ligeiras modificações nos "Aforismos") entre aquilo que alguém é, tem ou representa. A questão central encontra-se na defesa de que a felicidade depende muito mais da primeira dimensão do que das outras duas. Ela é descrita por Schopenhauer como sinônimo de uma autarquia do indivíduo em relação ao mundo externo, mas é uma noção que traz intrínseca a si um pressuposto pessimista por ser dependente de um componente que não pode ser decidido:

[...] se por um lado o componente subjetivo, a personalidade, é o mais essencial [para a felicidade], por outro lado, a dificuldade se apresenta no fato de que tal componente subjetivo encontra-se totalmente fora de nosso poder, assim como mantém-se estável e imutável por toda a vida (HN III, "Foliant II", § 270, p. 384, grifo meu). 
É então que o papel do conhecimento aprofundado do caráter (ou autoconhecimento), no sentido do caráter adquirido, nevrálgico para a eudemonologia, passa a ser tomado como alternativa. O caráter adquirido (erworbenen Charakter) pode ser considerado o principal elemento da sabedoria de vida na medida em que torna possível uma consideração do indivíduo pautada, sobretudo, nas ideias de experiência adquirida, de autoconhecimento e de instrução do intelecto, noções configuradoras da porção "melhorável" de cada individualidade, dimensão da personalidade conquistada pela experiência consigo mesmo, com os outros e em sociedade. Embora elaborado de forma definitiva no $\S 55$ de "O mundo", de 1819, o conceito foi registrado pela primeira vez no fragmento póstumo 595, de 1816, nos seguintes termos:

$\mathrm{O}$ que as pessoas comumente elogiam como caráter e que se adquire mediante o comércio com o mundo diferencia-se tanto do caráter inteligível quanto do empírico [...]. Quem não possui um caráter adquirido, frequentemente tentará ser outro em relação ao que é: este alguém está condenado ao fracasso e o fracasso expõe suas debilidades, o que causa muita dor. [...]. No entanto, dado que o descontentamento consigo mesmo é o sofrimento mais amargo, e dado que se pode dele fugir na medida em que se sabe o que se é, então quem assim o faz será muito mais feliz mediante um autoconhecimento perfeito (vollkommne Selbsterkenntniß), esta satisfação do gnothi seauton, que se chama caráter adquirido (HN I, "Die Genesis des Systems", § 595, pp. 400-402, grifos meus).

É preciso notar, porém, que a conquista do caráter adquirido como um "autoconhecimento perfeito" ou como "o conhecimento mais acabado possível da própria individualidade" (Schopenhauer, MVR I, § 55, p. 394) é algo para uma vida inteira, depende da experiência dos anos vividos, e só é galgado mediante muitos esforços e renúncias. Podemos notar nas entrelinhas do $\S$ 55 de "O mundo" e dos "Aforismos" que essa conquista tem como condição uma experiência dolorosa sobre "o que queremos e o que podemos fazer", sem a qual - observa o pensador - "muitas vezes, por meio de duros golpes exteriores, temos de retroceder em nosso caminho" (ibidem, p. 393). Outra metáfora de "O mundo" diz que, antes de alcançarmos o autoconhecimento do caráter adquirido, "andamos em zigue-zague, ao sabor dos ventos, sem chegar a lugar nenhum” (ibidem, p. 392). Esse também é o sentido da seguinte metáfora dos "Aforismos": "Assim como o andarilho precisa subir num cume para ter uma visão panorâmica do caminho percorrido [...], com todas as suas voltas e tortuosidades, nós também só reconhecemos a verdadeira concatenação de nossas ações [...] ao final de um período de nossa vida ou até mesmo da vida inteira" (Schopenhauer, 1851b, p. 153, grifo meu). Se essas condições para se alcançar o caráter adquirido revelam a parcela pessimista da esfera eudemonológica dessa filosofia, o aspecto pragmático de tal pessimismo pode ser reconhecido 
quando o filósofo afirma que, quanto à personalidade, "a única coisa que está ao nosso alcance é utilizá-la do modo mais vantajoso possível" (HN III, "Foliant II", § 270, p. 385, grifos meus); em outros termos, tudo o que podemos fazer é "empregar a personalidade (die Persönlichkeit benutzen), tal qual nos foi dada, para os maiores proveitos possíveis" (Schopenhauer, 1851b, p. 11, grifos meus), mesmo que estes sejam sempre incertos ante a natureza positiva do sofrimento, e mesmo que a personalidade não seja determinada por nós.

3. Outra expressão dessa face peculiar do pessimismo schopenhaueriano pode ser identificada no próprio conteúdo predominante das máximas dos "Aforismos" que, no geral, diz respeito à prudência, à dosagem de expectativas e à capacidade de suportar o sofrimento, conforme lemos no capítulo $\mathrm{V}$ desse escrito. Neste capítulo, Schopenhauer divide seus conselhos e exortações em "máximas gerais" e máximas que dizem respeito à nossa conduta em relação "a nós mesmos", "aos outros" e, por último, "ao curso do mundo e do destino". A característica mais relevante (destacada na máxima $\mathrm{n}^{\circ} 1$ ) do indivíduo "sábio" que considera as adversidades do mundo em sua busca por bem-estar repousa na noção de prudência. Ela é tomada como a "regra suprema de toda a sabedoria de vida" e é mencionada a partir da formulação de Aristóteles da "Ética a Nicômaco" (VII, 12): "O prudente aspira não ao prazer, mas à ausência de dor" (der Vernünftige geht auf Schmerzlosigkeit, nicht auf Genu $\beta$ ) (ibidem, p. 140, grifos meus). É preciso tomar esta referência à filosofia antiga ${ }^{17}$ em sintonia com a concepção schopenhaueriana de que a satisfação da vontade sempre faz efeito apenas negativamente. Sob este viés, a noção de prudência na obra de Schopenhauer ${ }^{18}$ adquire o sentido de um método ou de um procedimento prático em vista de uma vida "menos infeliz", ou seja, de um estado de "ausência de dor" ou de "ausência de dores excessivas", única espécie de felicidade possível. Sua principal atuação consistiria em reconhecer as penúrias e a insatisfação do querer, desdobrando-se num posicionamento prático que restringe racional e intencionalmente a busca por prazeres. Do ponto de vista eudemonológico

$17 \mathrm{Na}$ "Crítica da filosofia kantiana" Schopenhauer entende a prudência a partir de uma referência ao estoico Cícero e a identifica com sua concepção de razão prática: "O que, nesse sentido, se chama razão prática é muito aproximadamente designado pela palavra latina prudentia [...]” (MVR I, p. 644, grifos do autor).

18 Mesmo citando a tradição antiga (como Aristóteles e o Estoicismo), Schopenhauer não prima por empregar o

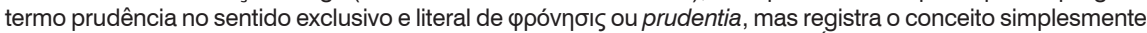
como Klugheit ou como Vernünftigkeit. Note-se que quando cita a máxima da Ética a Nicômaco - "O prudente aspira não ao prazer, mas à ausência de dor" - como "regra suprema de toda a sabedoria", Schopenhauer

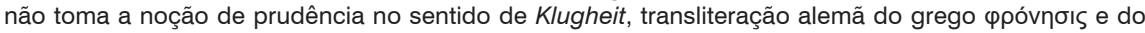
latim prudentia. O "prudente" é ali considerado como Vernünftige, de Vernünftig, termo este que, embora também corresponda a prudentia, pode ser traduzido por sensatez ou por razoabilidade. Afirma o filósofo, em uma nota sobre o assunto: "A versão latina da sentença é fraca [isto é, quod dolore vacat, non quod suave est, persequitur vir prudens]; em alemão, ela pode receber uma tradução melhor: der Vernünftige geht auf Schmerzlosigkeit, nicht auf Genuß" (Schopenhauer, 1851b, p. 140). 
negativo, afirma o filósofo, "aprendemos a adaptar-nos à imperfeição de todas as coisas e condições, e enfrentarmos os acidentes, a fim de evitá-los ou suportá-los" (Schopenhauer, 1851b, p. 241, grifos meus).

No amplo leque dos conselhos em favor de uma vida menos infeliz, a máxima 16 do mesmo cap. V dos "Aforismos" destaca a importância de limitarmos os desejos, refrearmos a cobiça, domarmos a cólera etc., tendo presente que "só podemos alcançar uma parte infinitamente pequena das coisas desejáveis, enquanto males múltiplos têm de ferir-nos" (ibidem, p. 190); trata-se de uma referência direta à máxima abstinere et sustinere (abster-se e suportar), de Epicteto. Outra máxima destacada pelo filósofo é a da adequação de nossas expectativas em relação ao mundo: "erra muito menos quem, com olhar sombrio, considera esse mundo como uma espécie de inferno e, portanto, só se preocupa em conseguir um recanto à prova de fogo" (ibidem, p. 142, grifo meu). A insensatez residiria na tentativa de transformar o "teatro de penúrias" do mundo num local de prazeres. Ao invés disso, o melhor que o mundo teria a oferecer seria "uma existência sem dor, tranquila, suportável [...]" (ibidem, p. 145), a cuja existência teríamos de limitar nossas expectativas a fim de termos mais chances de concretizá-las. Nesse sentido, lemos também que "[...] é aconselhável reduzir a uma escala bem modesta as expectativas de prazer, posse, posição, honra etc. [...]. Tal redução é prudente e oportuna porque ser muito infeliz é deveras fácil; já ser muito feliz não é só difícil, mas totalmente impossível" (idem, grifos meus). Vislumbramos, com isso, que não obstante a consciência de que nossa existência é algo que seria melhor se não fosse, a sabedoria de vida ainda poderia tornar tal existência suportável. Não é difícil notar, entretanto, a natureza limitada de tal sabedoria, constatação que pode ser realçada quando percebemos que, mesmo num texto sobre a felicidade como os "Aforismos", o pensador registra como "suprema sabedoria" a negação e a rejeição da existência, algo que só é alcançável, porém, por raros ascetas e santos.

Ora, se o conteúdo das máximas acima destacado indica a face de um pessimismo schopenhaueriano do âmbito eudemonológico - aqui denominado pessimismo pragmático -, deparamo-nos ainda mais com um tal pessimismo quando lemos a formulação do final da Introdução dos “Aforismos” (1851b, p. 2):

Em geral, os sábios de todos os tempos disseram sempre o mesmo, e os tolos, isto é, a imensa maioria de todos os tempos, sempre fizeram o mesmo, ou seja, o contrário; e assim continuará a ser. Por isso, diz Voltaire: Nous laisserons ce monde-ci aussi sot et aussi méchant que nous l'avons trouvé en y arrivant [Deixaremos esse mundo tão tolo e tão mau quanto o encontramos ao aqui chegar]. 
Esta surpreendente afirmação do filósofo sobre os efeitos dos conselhos dos "sábios de todos os tempos" vale também para as suas próprias máximas de sabedoria de vida, uma vez que, como afirma em outra ocasião, os "Aforismos" visariam "semear um suplemento nesse imenso campo já por outros trabalhado" (ibidem, p. 136). E, se é assim, não seria desarrazoado assumir que a asserção acima citada representa bem a natureza - pessimista - da projeção do autor sobre os efeitos de sua eudemonologia eufemística em vista da árida travessia do indivíduo pelo "pior dos mundos possíveis".

\section{Considerações finais}

De acordo com o exposto, podemos afirmar que o pessimismo da esfera pragmático-eudemonológica, aqui denominado pessimismo pragmático, é suplementar em relação à dimensão propriamente metafísica da existência humana e, por conseguinte, ao chamado pessimismo metafísico do pensamento schopenhaueriano. A hipótese de um pessimismo pragmático pode auxiliar na delimitação do famigerado - mesmo que pouco circunscrito - pessimismo schopenhaueriano. Ela é apropriada na medida em que a sabedoria de vida é considerada como domínio das estratégias empregadas pragmática e especificamente a fim de se obter "o máximo possível de felicidade", ou o mínimo possível de infelicidade, mas nos moldes delineados por uma eudemonologia negativa e eufemística, ou seja, não como superação do pessimismo metafísico, mas como estratégia que o pressupõe em outro patamar. Tratar-se-ia de uma espécie de "adaptação" ao âmbito prático de alguns pressupostos, como o da imutabilidade do caráter. Com isso, o pessimismo metafísico, que pode ser tomado pelo mote "é impossível ser feliz" (sendo possível, ao invés disso, apenas negar a vontade em graus variados), não é integralmente abandonado por ocasião do mencionado "desvio" da metafísica. Ao contrário, ele é "adaptado" para o caso de uma prática de vida que, a partir de então, pauta-se no mote segundo o qual "é possível ser menos infeliz".

Conforme procurei mostrar, na medida em que é delineada nos "Aforismos" enquanto oferta de máximas para o homem ser o "menos infeliz" possível, a eudemonologia estaria em plena sintonia com a teoria expressa principalmente em "O mundo", segundo a qual cada indivíduo, como esboço fugidio traçado pela vontade permanente, tem seu preço pago "com muitas e profundas dores e, ao fim, com uma amarga e profunda morte, longamente temida [...]" (Schopenhauer, MVR I, § 58, p. 414). Ora, esta eudemonologia elaborada a partir de um "desvio" do ponto de vista superior e metafísico da filosofia não representaria, pois, nenhum "desvio" do pessimismo, dado que o filósofo já parte de uma convicção 
pessimista de que a sabedoria de vida só pode ter em vista o enfrentamento, com estratégia, das misérias humanas. As indicações de máximas representariam uma continuação do pessimismo (e não o ingresso num otimismo), desta vez no patamar pragmático. Haveria, nesse sentido, uma espécie de pessimismo "eudemonológico-pragmático" que continuaria sendo um pessimismo devido à natureza negativa e eufemística de suas máximas de sabedoria.

Desse modo, podemos concluir que analisar o pensamento schopenhaueriano sem levar em conta o seu perfil pragmático-eudemonológico implicaria tomar esse pessimismo de forma parcial. A eudemonologia representaria uma face menos titânica de um pensamento que, se penetrara até o âmago do caráter absurdo, grundlos, e irremediável do mundo, também deixou ao "homem do mundo" a sabedoria de vida como sugestão de conduta. Tratar-se-ia de duas perspectivas de leitura de um mesmo objeto, ou seja, da própria natureza volitiva e sem fundamento do micro e do macrocosmos, cujos intentos podem ser diferenciados de forma ilustrativa pelas metáforas cunhadas por dois contemporâneos de nosso filósofo: por um lado, Jean Paul comparou "O mundo como vontade e como representação" a um malincônico lago norueguês, cercado por altas rochas, no qual o Sol nunca se espelha, mas somente o céu estrelado. Por outro, o poeta Adalbert von Chamisso sugeriu pessoalmente a Schopenhauer, em Berlim, que a "cor" com a qual este havia "pintado o mundo" não precisaria ser a preta, bastando para tanto um cinza-escuro (cf. Schopenhauer, 2000, p. 79). A imagem do lago norueguês poderia representar tanto as dores do mundo e a impossibilidade de melhoria do caráter humano quanto a ideia de resignação à qual conduz o ascetismo, o pessimismo metafísico imanente que "não está ao Sol", muito embora este exista. Já a metáfora de Chamisso ilustraria a concepção de que o mundo pode ser expresso com "cores mais suaves", o que, de certa forma, Schopenhauer indicou com sua peculiar eudemonologia - uma outra face de um mesmo pessimismo.

\section{Referências}

\section{Obras de Schopenhauer}

SCHOPENHAUER, A. (1840). "Sobre o fundamento da moral". Tradução de Maria Lúcia Cacciola. São Paulo: Martins Fontes, 2001.

SCHOPENHAUER, A. (1851a). "Parerga e paralipomena". Tomo II. Tradução brasileira dos capítulos 1 a 7 ("Sobre a filosofia e seu método") e dos capítulos 8 a 15 ("Sobre a ética") de Flamarion Caldeira Ramos. São Paulo: Hedra, 2010.

SCHOPENHAUER, A. (1851b). "Aforismos para a sabedoria de vida". Tradução de Jair Barboza. São Paulo: Martins Fontes, 2006. 
SCHOPENHAUER, A. (1859). "O mundo como vontade e como representação". Tomo I. Tradução de Jair Barboza. São Paulo: Unesp, 2005.

SCHOPENHAUER, A. (1911-1941a). "Sämtliche Werke”. Hrsg. von Paul Deussen. 16 Bände. München: Piper Verlag. In: Schopenhauer im Kontext III - Werke, Vorlesungen, Nachlass und Briefwechsel auf CD-ROM, Release 2008.

SCHOPENHAUER, A. (1911-1941b). "Die Welt als Wille und Vorstellung". Band II. In: Sämtliche Werke. Hrsg. von Paul Deussen. 16 Bände. München: Piper Verlag. Schopenhauer im Kontext III - Werke, Vorlesungen, Nachlass und Briefwechsel auf CD-ROM, Release 2008.

SCHOPENHAUER, A. (1911-1941c). "Der Handschriftliche Nachlass". In: Sämtliche Werke. Hrsg. von Paul Deussen. 16 Bände. München: Piper Verlag. Schopenhauer im Kontext III - Werke, Vorlesungen, Nachlass und Briefwechsel auf CD-ROM, Release 2008.

SCHOPENHAUER, A. (1911-1941d). "Über den Willen in der Natur”. In: Sämtliche Werke. Hrsg. von Paul Deussen. 16 Bände. München: Piper Verlag. Schopenhauer im Kontext III - Werke, Vorlesungen, Nachlass und Briefwechsel auf CD-ROM, Release 2008.

SCHOPENHAUER, A. "Colloqui”. A cura di Anacleto Verrechia. Milano: Bur Rozzoli, 2000.

SCHOPENHAUER, A. "A arte de ser feliz". Organização de Franco Volpi; tradução de Eduardo Brandão. São Paulo: Martins Fontes, 2008.

SCHOPENHAUER, A. "L'arte di essere felici". A cura di Franco Volpi, traduzione di Giovanni Gurisatti. 29a ed. Milano: Adelphi, 2012.

Outras referências

BARBOZA, J. "Em favor de uma boa qualidade de vida". In: SCHOPENHAUER, A. Aforismos para a sabedoria de vida. $2^{\mathrm{a}}$ ed. Tradução de Jair Barboza. São Paulo: Martins Fontes, 2006. pp. IX-XVIII.

. "Uma filosofia do consolo". In: SCHOPENHAUER, A. Metafísica do amor, metafisica da morte. Tradução de Jair Barboza. São Paulo: Martins Fontes, 2000. pp. VII-XXIII.

BRUM, J. T. "O pessimismo e suas vontades: Schopenhauer e Nietzsche". Rio de Janeiro: Rocco, 1998.

CHEVITARESE, L. "A ética em Schopenhauer: que 'liberdade nos resta' para a prática de vida?" Tese de Doutorado. Pontifícia Universidade Católica do Rio de Janeiro, Rio de Janeiro, 2005.

DEUSSEN, P. “Bericht über Hegel und Schopenhauer". Berlin: Reimer, 1980. (Archiv für Geschichte der Philosophie, 3).

DÖRPINGHAUS, A. "Mundus pessimus: Untersuchungen zum philosophischen Pessimismus Arthur Schopenhauers". Würzburg: Königshausen \& Neumann, 1997.

FAZIO, D. "La 'scuola' di Schopenhauer. Per la storia di un concetto". In: Arthur Schopenhauer e la sua scuola. A cura di F. Ciracì, D. Fazio e F. Pedrocchi. Lecce: Pensa Multimedia, 2007. pp. 35-76. (Schopenhaueriana, 1). 
. "La scuola di Schopenhauer: i contesti". In: La scuola di Schopenhauer: testi e contesti. A cura del Centro interdipartimentale di ricerca su Arthur Schopenhauer e la sua scuola dell'Università del Salento. Lecce: Pensa Multimedia, 2009. pp. 13-212. (Schopenhaueriana, 2).

GERHARDT, V. "Pessimismus". In: Historisches Wörterbuch der Philosophie. Hrsg. von J. Ritter; K. Gründer. Band 7. Basel: Schwabe \& Co. Verlag, 1989. pp. 386-395. HORKHEIMER, M. "Die Aktualität Schopenhauers". In: Schopenhauer-Jahrbuch. Band. 42, 1961. pp. 12-25.

INVERNIZZI, G. "Il pessimismo tedesco dell'Ottocento: Schopenhauer, Hartmann, Bahnsen e Mainländer e i loro avversari”. Firenze: La Nuova Italia, 1994.

KÖHLER, F. "Schopenhauer und das Wesen des Pessimismus und Optimismus". Langensalza: H. Beyer, 1926.

LÜTKEHAUS, L. "Schopenhauer, metaphysischer Pessimismus und 'soziale Frage"”. Bonn: Bouvier Verlag, 1980.

MALTER, R. "Arthur Schopenhauer. Transzendentalphilosophie und Metaphysik des Willens". Stuttgart-Bad Cannstatt: Frommann-Holzboog, 1991.

NIETZSCHE, F. "Ecce Homo: como alguém se torna o que é". Tradução de Paulo César de Souza. São Paulo: Companhia das Letras, 2008.

. "Crepúsculo dos ídolos, ou, Como se filosofa com o martelo". Tradução de Paulo César de Souza. São Paulo: Companhia das Letras, 2006.

. "Para além de Bem e Mal: prelúdio a uma filosofia do futuro". Tradução de Paulo César de Souza. São Paulo: Companhia das Letras, 2005.

. "Para a genealogia da moral: uma polêmica". Tradução de Paulo César de Souza. São Paulo: Companhia das Letras, 1998.

SAFRANSKI, R. "Schopenhauer und die wilden Jahre der Philosophie". 6a Auf. Frankfurt a. M.: Fischer, 2010.

STÄGLICH, H. “Zur Geschichte des Begriffs Pessimismus”. In: Schopenhauer-Jahrbuch. Bd. 34, 1951/1952. pp. 27-37.

VIESENTEINER, J. L. “'Prudentia' e o uso prático da razão em Schopenhauer”. Revista Voluntas: Estudos sobre Schopenhauer, Rio de Janeiro, Vol. 3, Nr. 1 e 2, pp. 3-19, $1^{\circ}$ e $2^{\circ}$ semestres de 2012.

VOLPI, F. "Introduzione". In: SCHOPENHAUER, A. L'arte di essere felici. $29^{\mathrm{a}}$ ed. Milano: Adelphi, 2012.

. "Apresentação". In: SCHOPENHAUER, A. A arte de ser feliz. São Paulo: Martins Fontes, 2008.

. "Presentazione". In: SCHOPENHAUER, A. I manoscritti berlinesi (18181830). Vol. III. A cura di Giovanni Gurisatti. Milano: Adelphi, 2004. 